\title{
MENOPAUSE, ESTROGENS, AND ENDOTHELIAL DYSFUNCTION: CURRENT CONCEPTS
}

\author{
Maria Augusta Maturana, Maria Claudia Irigoyen, Poli Mara Spritzer
}

\begin{abstract}
Maturana MA, Irigoyen MC, Spritzer PM. Menopause, estrogens, and endothelial dysfunction: current concepts. Clinics. 2007;62(1):77-86.

Menopause is defined as the permanent cessation of menses. Cardiovascular disease is the leading cause of death among postmenopausal women in developed countries. The disparity between the incidence of cardiovascular disease among women in pre- and postmenopause has been ascribed to the actions of endogenous estrogen on the cardiovascular system and, particularly, on the vascular endothelium. The endothelium plays an important role in cardiovascular homeostasis, either through the vascular tonus and its regulation, or through coagulation and the inflammatory response. Endothelial dysfunction is implicated in the genesis of atherosclerosis and other chronic disorders, such as diabetes mellitus and hypertension. The pharmacological use of estrogen exerts influence on the circulating levels of markers of vascular tonus, and inflammation, as well as prothrombotic, and fibrinolytic markers, but the impact of these changes on the atherosclerotic disease is still uncertain.
\end{abstract}

KEYWORDS: Menopause. Endothelial function. Cardiovascular disease. Estrogen. Hormone therapy.

Menopause is defined by the World Health Organization as the permanent cessation of menses as a result of the loss of ovarian follicular function or of surgical removal of ovaries. ${ }^{1}$ The mean age for occurrence of natural menopause is around 50 years. ${ }^{1,2}$

The management of the menopausal patient has been a matter of great concern in the last decades, both in terms of epidemiology and public health and in terms of medical scientific research. This is largely due to improved life expectancy, which allows the prediction that women may live a third of their lifetimes after menopause. Demographic studies indicate that worldwide in 1990, about 467 million women were at age 50 or over. For the year 2030, the estimate is that this group will exceed 1200 million women. ${ }^{3}$

Gynecological Endocrinology Unit, Division of Endocrinology, Hospital de Clínicas de Porto Alegre - Porto Alegre, Brazil.

Department of Physiology, Universidade Federal do Rio Grande do Sul Porto Alegre, Brazil.

Email: spritzer@ufrgs.br

Received for publication on August 24, 2006.

Accepted for publication on October 16, 2006.
The hormonal changes that accompany menopause, particularly the decreased levels of estrogen hormones, have a great physiological impact. Estrogen deficiency has been associated with vasomotor symptoms, urogenital atrophy, and cognitive impairment, as well as increased risk of chronic degenerative diseases such as osteoporosis and Alzheimer's disease.

\section{MENOPAUSE AND CARDIOVASCULAR DISEASE}

Cardiovascular disease remains the leading cause of death in the 21 st century. ${ }^{4}$ Despite the advances in this area, it is still the main cause of death among women in developed countries. In the United States, over half a million women die of cardiovascular disease every year, exceeding the number of deaths among men and the total of the subsequent leading causes of death among women. Coronary arterial disease is responsible for most of the deaths by cardiovascular disease among women. ${ }^{5}$ Moreover, women have a less favorable prognosis than men with respect to a coronary event: $40 \%$ of the total coronary events in women are deadly, and $67 \%$ of sud- 
den deaths occur in women without a history of coronary disease. ${ }^{5}$

The prevalence of cardiovascular disease in premenopausal women is smaller than in postmenopausal women, when there is an exponential increase, causing the risk for women to equal that for men by the age of 70 years. This lag concerning the age period at which the frequency of cardiovascular events increases among women as compared to men has been ascribed to the actions of endogenous estrogen on the cardiovascular system, through mechanisms as yet not completely clarified.

The beneficial influence of hormone therapy (HT) during menopause on the cardiovascular comorbidities is not well-established. Observational studies have found a reduction of up to $50 \%$ in the risk of cardiovascular disease in postmenopausal women using HT. ${ }^{7-9}$ However, the results of 2 large randomized prospective studies refute the claims of cardioprotective effects of hormone therapy based on observational studies. The Heart and Estrogen/ Progestin Replacement Study (HERS) was a randomized clinical trial designed to test the effectiveness of HT in the secondary prevention of coronary heart disease. The results indicate an increase in the coronary events within the first year of follow-up after acute myocardial infarction among patients treated with a combination of conjugated estrogens/medroxy progesterone acetate at fixed doses and mean age of 66.7 years. ${ }^{10}$ Recently, the Women's Health Initiative (WHI), a prospective study of primary prevention of cardiovascular disease, was interrupted early because a higher incidence of cardiovascular events was demonstrated among the women randomized for use of HT than in the group receiving placebo. In this study, although HT was associated with reduced risk of colorectal cancer and bone fracture, it was also associated with increased risk of breast cancer. ${ }^{11}$ Finally, in 2004 the results of the therapeutic arm of the WHI evaluating the isolated use of conjugated estrogens versus placebo among 10739 hysterectomized postmenopausal women were published. There was an increased risk of cerebral vascular accident ( $\mathrm{rr}=1.39 \mathrm{CI}$ : 110-177), but a decreased risk of hip fracture and null effect on the incidence of cardiovascular disease, as well as potential reduction in the incidence of breast cancer. Overall, the risk-benefit index was neutral. ${ }^{12}$

The well-known risks for cardiovascular disease, such as systemic hypertension, smoking, obesity, sedentary life style, dyslipedemia, stress, family history of cardiovascular disease, diabetes mellitus, and insulin resistance, are numerous. ${ }^{6}$ More recently, endothelial vascular dysfunction has become suspected as being associated with cardiovascular disease, as detailed below.

\section{THE ENDOTHELIUM}

The endothelium is a layer of cells lining all the vessels of the organism and placing itself between the blood and the vascular smooth muscle layer. The endothelial cells form the more exposed surface of the inner vascular layer, presenting selective permeability, having a nonthrombogenic character, exhibiting exuberant metabolic activity, and having the ability to produce several vasoactive substances. ${ }^{13}$

The main actions exerted by the endothelium can be described as the following:

- Selective permeability: The endothelium forms a highly selectively permeable barrier, regulating the flow of nutrient substances, many biologically active molecules, and blood cells. ${ }^{14}$

- Maintenance of a balance between thrombosis and fibrinolysis: The endothelium normally provides a nonthrombogenic surface due to its ability to form prostaglandin derivatives, especially prostacyclin, which is a potent vasodilator and an effective inhibitor of platelet aggregation. ${ }^{15}$ The endothelial cells also secrete agents (including plasminogens) that are effective in the lysis of coagula, but they also synthesize procoagulant agents such as Von Willebrand factor (vWF). Additionally, they produce thrombogenic substances such as coagulation factors, adhesion molecules, plasminogen activator inhibitor-1 (PAI-1), and tromboxan A2. ${ }^{16}$

- Inhibition of cell proliferation of vascular smooth muscles, preventing the migration of smooth muscle cells through direct mechanisms, such as synthesis of nitric oxide, which inhibits cell proliferation, and/or indirect ones (platelet action). ${ }^{17,18}$

- Active participation in immune response through the release of factors leading to active contraction, control of plasma extravasation, as well as increase in the expression of integrins, molecules of adhesion and secretion of cytokines, allowing the migration of monocytes, lymphocytes, and neutrophils and greater local phagocytic activity.

- Modulation of vascular tonus through the production of numerous vasoactive substances (Table 1). The regulation of the vasomotor tonus is determined by a balance

Table 1 - Endothelial-derived vasoactive factors ${ }^{21}$

\begin{tabular}{ll}
\hline Vasodilator Factors & Vasoconstrictor Factors \\
\hline - Nitric oxide (NO) & $\bullet$ Endothelin $(\mathrm{ET})$ \\
- Endothelium-derived & $\bullet$ Prostanoids $\left(\mathrm{PGH}_{2}, \mathrm{TXA}_{2}, \mathrm{O}_{2}\right)$ \\
& hyperpolarizing factor (EDHF) \\
- Prostacyclin $\left(\mathrm{PGI}_{2}\right)$ & $\bullet$ Angiotensin (AII) \\
- Acetylcholine & \\
- Bradykinin & \\
\hline
\end{tabular}


of dilation and constriction. Nitric oxide (NO) is the main mediator of vasomotor tonus in physiological situations. Some stimuli, such as the dragging force produced by the pulsatile blood flow, the pressure of blood against the vascular wall, and the shear stress, contribute to the basal generation of NO. ${ }^{19-21}$

\section{ENDOTHELIAL DYSFUNCTION}

The term endothelial dysfunction is more frequently used to mean reduction in endothelium-dependent vasodilatation, associated with diminished bioactivity of local vasodilating factors, especially nitric oxide, but it probably includes other normal functions of the endothelium such as interaction with leukocytes, platelets, and regulatory substances. Currently, it is a consensus that endothelial dysfunction is the initial event in development of atherosclerosis. ${ }^{22}$ Several conditions such as aging, menopause, dyslipedemia, high blood pressure, and diabetes mellitus are associated with endothelial dysfunction. ${ }^{23-27}$

\section{TECHNIQUES FOR EVALUATION OF ENDOTHELIAL FUNCTION}

There are many techniques for investigating the endothelium, from those that focus on cellular and molecular aspects, through methods involving tissue culture and molecular biology tools, to clinical trials applied to human beings, using invasive and noninvasive procedures to evaluate endothelium-dependent vasodilatation, or the determination of plasmatic substances that indicate endothelial activation and damage (Tables 2 and 3).

Table 2 - Markers of endothelial function ${ }^{24,91}$

\begin{tabular}{ll}
\hline Endothelial Function & Marker \\
\hline Coagulation & Fibrinogen \\
& $\bullet$ vWF \\
& TXA \\
\hline Fibrinolysis & t-PA \\
\hline Inflammation & PAI-1 \\
& CRP \\
& E-selectin \\
& ICAMrinogen \\
& IL-6 \\
\hline Vascular Tonus & Plasma Markers \\
& - ET-1 \\
& - NO
\end{tabular}

vWF: von Willebrand factor; TXA $_{2,:}$ tromboxan; $\mathrm{A}_{2 ;}$ tPA: tissue plasminogen activator; PAI-1: plasminogen activation inhibitor-1; CRP: C-reactive protein; ICAMs: intercellular adhesion molecules; VICAMs: vascular cell adhesion molecules; IL-6: interleukin 6; ET-1: endothelin-1; NO: nitric oxide
Table 3 - Functional tests for endothelial-dependent vasodilation evaluation ${ }^{24,90}$

\begin{tabular}{ll}
\hline Functional Tests \\
\hline Invasive & $\begin{array}{l}\text { Coronary angiography } \\
\text { Pletismography }\end{array}$ \\
§Noninvasive & $\begin{array}{l}\text { Positron emission tomography } \\
\text { FMD } \\
\text { Brachial artery ultra-son } \\
\text { Pletismography and dorsal hand vein } \\
\text { compliance method }\end{array}$ \\
\hline
\end{tabular}

FMD: flow-mediated vasodilation

Intracoronary studies evaluating endothelium-dependent vasodilatation after infusion of acetylcholine are considered gold standard techniques in assessing endothelial function, but their invasive character precludes their largescale use. ${ }^{22}$ Thus, taking into account that endothelial dysfunction is present at early stages of atherosclerosis and that it involves several arteries, noninvasive tests in the peripheral circulation have been increasingly used. ${ }^{25}$ Three techniques are particularly useful for estimating the endothelial dysfunction in peripheral circulation: ultrasonography of brachial artery, impedance pletismography, and dorsal hand vein compliance. Each of these techniques evaluates the endothelial function indirectly by measuring changes to the size of brachial artery, forearm veins, and back of the hand, respectively, after physical (active hyperemia) or pharmacological stimulation (bradykinin or acetylcholine).

\section{ULTRASONOGRAPHY OF BRACHIAL ARTERY}

Flow-mediated dilatation (FMD) can be measured through high resolution ultrasonography. This technique contrasts the changes in the diameter of the brachial artery in response to the increased flow induced by reactive hyperemia and sublingual nitrate. Vasodilating responses are expressed as a percentage of change to the size of the vessel (basal and following stimulation). In 1994 Celermajer et $\mathrm{al}^{28}$ studied more than 500 healthy individuals using FMD and demonstrated negative association between FMD and a variety of cardiovascular risk factors, such as smoking, hypertension, age, and hypercholesterolemia. Other studies have demonstrated a positive correlation between FMD and central hemodynamic parameters as well as the extent and prognosis of the coronary disease..$^{29,30}$

Although FMD has been used in several studies, it has limitations related to environmental and individual factors, such as prandial state and arterial size. ${ }^{31}$ Also, problems related to reproducibility and intraobserver variation are mat- 
ters of debate in the literature. Rossi et al, ${ }^{32}$ demonstrated variation coefficients of $3.3 \%$ and $12.4 \%$, respectively, for basal size and after stimulation of the brachial artery.

There is as yet no consensus in literature about the parameters of normality for FMD. Ryliskyte et $\mathrm{al}^{33}$ analyzed 115 individuals with low cardiovascular risk and found that the only independent predictors of FMD were age and vessel size. Therefore, these authors suggest that in analyzing results, normal ranges according to age and the caliber of the tested vessel must be taken into account.

\section{IMPEDANCE PLETHYSMOGRAPHY AND DORSAL HAND VEIN COMPLIANCE}

Compliance and vein occlusion pletismography uses a sensor of stretching to quantify variations in volume in the forearm or lower limb, taking into account the fact that variations in volume in these parts are dependent on the local blood flow variation. Forearm blood flow (FBF) measurements can be done following ischemic (reactive hyperemia) or pharmacological stimulation, the latter requiring catheterization and drug infusion into brachial artery, which is an invasive procedure. Flow values can be calculated by manual or semi-manual analysis using specific software.

Forearm blood flow has been validated in several studies as a tool for evaluating the endothelial function. Diminished FBF is associated with increased thickness of the tunica media of the artery as well as presence of CAD and the risk factors associated with it. ${ }^{16,34,35}$ Forearm blood flow can also be used to monitor the changes to the endothelial function after interventions for cardiovascular risk factors. ${ }^{36}$

Environmental and physiological variables, such as room temperature, age, race, hormonal state, phase of menstrual cycle, anxiety, and prandial state, can influence the magnitude of FBF responses. Variation in FBF values in a single individual can be about $12.9 \%$, reflecting the influence of these variables. ${ }^{37,38}$ To minimize variability, the tests must be done in a silent room at a stable temperature, and the patient must be fasting.

The dorsal hand vein compliance technique uses measurements of venous diameter variations obtained through a linear transducer. Venodilatation curves are obtained after infusion of acetylcholine or bradykinin (endotheliumdependent vasodilatation) and nitrate (endothelium-independent vasodilatation) as compared to basal curves. ${ }^{39}$ Regarding safety, risks, and accuracy, the dorsal hand vein compliance technique is comparable to impedance plethysmography, although it has the advantage of using vasoactive substances at lower doses, thus avoiding potential sys- temic confounders. ${ }^{22}$ Again, the results are influenced by environmental and physiological factors. Greater reproducibility and smaller intrapatient variability of the test are related to preconstriction of the tested vessel, ideally about $80 \%$ of the vein constriction in the basal state $\left(\mathrm{ED}_{80}\right) .{ }^{39}$

\section{ESTROGEN, MENOPAUSE, AND ENDOTHELIAL FUNCTION}

There is evidence of an association between endothelial dysfunction and reduced endogenous production of estrogens after natural or surgical menopause or premature ovarian failure $(\mathrm{POF})$ in women with or without coronary arterial disease..$^{27,40-42}$

The actions of endogenous estrogens on the cardiovascular system can be mediated directly on the vessels or indirectly through the modulation of cardiovascular risk factors, as well as on the lipid profile (reduction of total cholesterol and LDL, increase in HDL), as already described more than 20 years ago. ${ }^{7}$ More recently, studies have also demonstrated an antioxidant effect by estrogen, reducing LDL oxidation in vivo and in vitro. ${ }^{43}$

The direct effects of estrogen on the vascular system and which modulate the vascular tonus comprise 1) acute vasodilatation, increasing the synthesis and bioactivity of nitric oxide; ${ }^{44,45}$ 2) long-term modulation of vascular tonus, regulating the production of prostaglandins and expression of eNOS and the endothelin gene ${ }^{46} ; 3$ ) inhibition of endothelin-induced vasoconstriction ${ }^{47}$; and 4 ) inhibition of sympathetic activity. ${ }^{27}$

In addition to these actions on the vascular tonus, estrogen exerts an antiproliferative action on the vascular smooth layer. ${ }^{48} \mathrm{Also}$, it appears to have a major role in vascular remodeling, inhibiting the proliferation of the inner layer after injury ${ }^{49}$ and increasing the expression of contractile proteins in the myocardium. ${ }^{50}$

In other tissues, such as the liver, estrogen can mediate both beneficial (expression of genes of apoproteins that improve the lipid profile) and adverse effects (increase in the expression of procoagulant factors and decrease of fibrinolytic factors). ${ }^{51}$

From the clinical point of view, our group has recently reported, in postmenopausal women who were not on hormone therapy, a positive association between nitric oxide and the free estradiol level, confirming the influence of this steroid on the endothelial function..$^{52}$

On the other hand, androgen and sex hormone-binding globulin (SHBG) levels have been associated with risk of cardiovascular disease in pre- and postmenopausal women. ${ }^{53,54}$ An increase in circulating androgens appears to be associated with insulin resistance and a predictor of 
diabetes mellitus. ${ }^{55-57}$ In a previous study, we demonstrated a positive association, independent of obesity, between testosterone levels and hyperinsulinemia in postmenopausal women with no clinical evidence of cardiovascular disease. $^{58}$

\section{HORMONE THERAPY AND ENDOTHELIAL FUNCTION}

Disturbances in endothelial function have an important role in the physiopathology of atherosclerosis, and several lines of evidence suggest that interventions in endothelial function could modify the progress rates of atherosclerotic disease and the risk of cardiovascular events. A number of studies have tested the impact of the use of HT on endothelial function using inflammatory and fibrinolytic/thrombogenic markers as well as functional methods. ${ }^{40,41,59,60,61}$

Results from the main randomized studies, HERS 2 and WHI, indicate increased risk of venous thromboembolism with the use of HT. ${ }^{8,62}$ It is important to note that these studies have been criticized in at least 2 respects: patient selection, which included women who were on average 10 years older than the age at which HT is usually recommended (WHI), and the use in both studies of a regimen of HT with fixed drugs, oral administration route and doses.

\section{Plama renin activity}

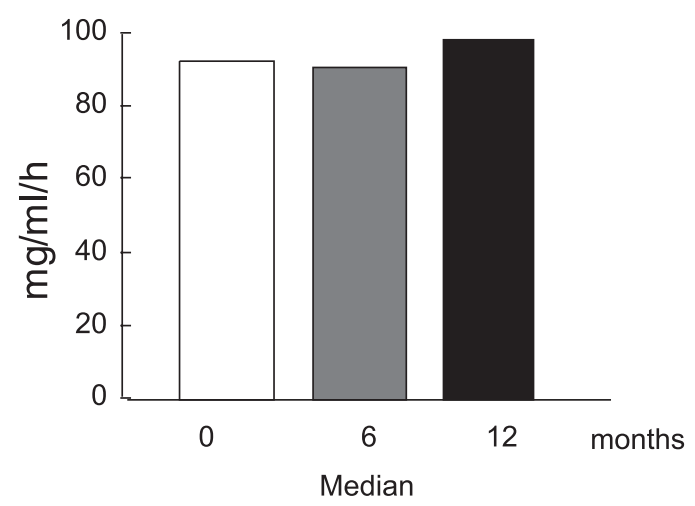

The administration route of HT appears to affect the fibrinolytic activity and the coagulation markers. The oral route for estrogen therapy is associated with changes in the levels of coagulation and fibrinolysis markers, especially at the early period of use. ${ }^{63-65}$ Studies using estrogen therapy by transdermal route, however, did not confirm these findings. ${ }^{66,67}$ Moreover, in a multicenter case-control study, Scarabin et al ${ }^{68}$ evaluated 155 postmenopausal women hospitalized because of venous thromboembolism (VTE) and demonstrated an increased risk for VTE with oral, but not with transdermal, therapy. Our group showed in postmenopausal patients that reduction of antithrombin III, usually seen with oral estrogen therapy, did not occur with the use of estradiol-17 $\beta$ in the form of percutaneous gel either alone $^{69}$ or in association with micronized progesterone ${ }^{71}$ (Figure 1). Plasma rennin activity was also similar before and during this non-oral hormone therapy (Figure 1). These findings have also shown that progesterone does not appreciably attenuate estradiol-induced beneficial effects.

In addition, we have recently shown that, in a sample of hypertensive postmenopausal women, the association of non-oral estradiol-17 $\beta$ and low doses of vaginal micronized progesterone for 1 year were effective on climacteric symptoms and safe regarding maintenance of blood pressure control and preventing endometrial hyperplasia. ${ }^{70,71}$ Moreover, in those patients, serial echocardiograph scans showed no

\section{Antithrombin III}

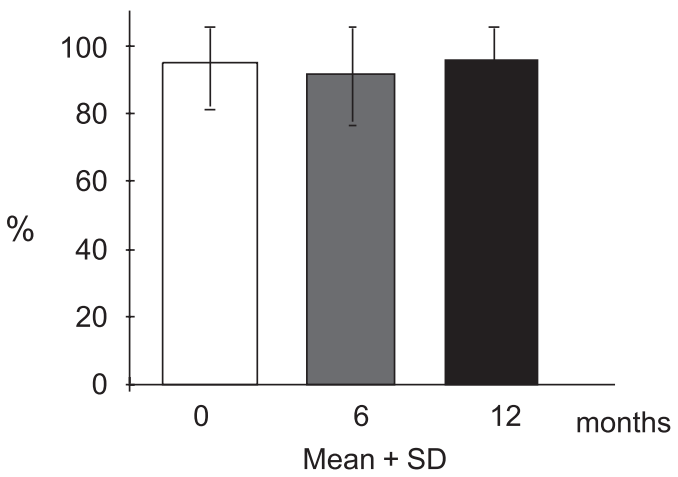

Figure 1 - Renin activity and antithrombin III in 20 postmenopausal women with mild to moderate hypertension, before and during 1 year of non-oral natural estradiol and low dose of micronized progesterone ${ }^{71}$

Table 4 - Echocardiographic variables in 20 hypertensive postmenopausal women ${ }^{71}$

\begin{tabular}{lcccc}
\hline & Before HT & 6-month & 12-month & \\
\hline Left ventricle posterior wall $(\mathrm{mm})$ & $9.1 \pm 0.4$ & $8.3 \pm 0.3$ & $8.0 \pm 0.2$ \\
Ejection fraction $(\%)$ & $71.3 \pm 1.3$ & $67.9 \pm 1.2$ & $69.4 \pm 1.5$ \\
Interventricular septum (mm) & $9.2 \pm 0.4$ & $8.9 \pm 0.4$ & NS & $8.2 \pm 0.2$ \\
\hline
\end{tabular}

Blood pressure control was achieved by administration of amlodipine at individually adjusted doses. Hormone therapy was introduced in a cyclic regimen (21 of 28 days) with percutaneous estradiol (1.5 mg/day) and vaginal micronized progesterone (100 mg/day). 
change in left ventricle mass, but a significant reduction in the thickness of the posterior wall of the left ventricle was observed ${ }^{71}$ (Table 4).

A number of studies have highlighted the effect of HT on endothelial inflammatory markers, such as decreased expression of adhesion molecules like ICAM-1, VICAM1, and E-selectin. ${ }^{72-74}$

Studies using the oral route have shown an increase in the circulating levels of C-reactive protein (CRP), a wellknown inflammatory marker. ${ }^{73-75}$ However, the clinical significance of these results has not been totally clarified. Other trials with non-oral routes reported, on the contrary, stability in CRP levels during HT. ${ }^{73,76}$

Acute non-oral use of estradiol may increase endothelium-dependent vasodilatation. ${ }^{77,78}$ Saitta et al ${ }^{79}$ compared the effects of using 17- $\beta$ estradiol plus norethisterone, raloxifene, or placebo for 6 months in postmenopausal patients. Treated women in both groups showed a significant increase in endothelium-dependent vasodilation measured by ultrasonography of brachial artery and in the plasmatic nitrite/nitrate levels, which was not observed in placebo users. A significant increase in the NO metabolites levels has also been shown by Balci et $a^{80}$ with the use of transdermal $17 \beta$ estradiol, $100 \mathrm{mg} /$ week for 3 months.

Although there is some evidence suggesting a favorable action of HT on vasomotor endothelial function, the longterm benefits on the natural history of atherosclerotic disease are as yet unknown. Ceballos et al ${ }^{81}$ showed a significant increase in endothelium-dependent vasodilation in menopausal patients treated with a combination of transdermal $17 \beta$ estradiol and micronized progesterone, but this benefit was lost after 6 months of drug discontinuation.

Few studies in the literature have addressed the question of the effect of progestogens on cardiovascular risk, and despite the well-recognized benefits of estrogens, controversy surrounds the risks and negative aspects of combined estrogen and progestogen use in HT.

The vascular actions of progestins and progesterone are mediated by progesterone receptors, expressed in endothelial cells and the vascular smooth muscle as well as through downregulation of the estradiol receptor. ${ }^{45}$ Concerning progesterone, evidence suggests that the natural molecule facilitates the inhibitory effects of estrogen on vascular smooth muscle proliferation $^{82}$ and may induce endothelium-dependent vascular relaxation. ${ }^{45,77}$ In addition, natural progesterone used in HT appears to preserve the beneficial actions of estrogen., ${ }^{8,70,71}$

Progestins present different pharmacological profiles according to their molecular structure, dosage, and to the presence of comorbidities. As with estrogens, the various progestins used in HT may differ significantly as to how closely they mimic their natural counterparts. For instance, progestin molecules with androgenic properties may antagonize estrogen-dependent beneficial effects on lipids, ${ }^{83}$ and a new molecule with antimineralocorticoid activity may reduce blood pressure in postmenopausal women with hypertension. ${ }^{84}$

Progestins added to estrogen therapy seem to increase inflammatory markers. ${ }^{72}$ In addition, medroxyprogesterone acetate associated with conjugated equine estrogens produces no effects ${ }^{85}$ or inhibits endothelium-dependent vasodilatation stimulated by estrogens. ${ }^{86}$ These observations have been taken to explain, at least in part, the adverse results observed in the large prospective, randomized, placebo-controlled trials of combined HT - the WHI and HERS studies. However, the extent to which findings of these studies of medroxyprogesterone acetate and conjugated equine estrogens apply to other HT formulations is unclear at present.

\section{ENDOTHELIAL DYSFUNCTION AND CARDIOVASCULAR DISEASE PREDICTORS IN MENOPAUSE}

Data from prospective trials have been confirming the hypothesis that endothelial dysfunction precedes the emergence of chronic disorders. The MONICA/KORA study (Monitoring of Trends and Determinants in Cardiovascular Disease/Cooperative Research in the Region of Augsburg), which involved more than 2000 patients, found an association between increased levels of E-selectin and I-CAM and increased risk of diabetes mellitus type 2 (DM2). ${ }^{87}$ In a follow-up study of 840 postmenopausal women, Rossi et $\mathrm{al}^{32}$ showed an adjusted relative risk for DM-2 of 5.87 (95\% confidence interval, 4.34-8.10) in patients in the lowest tertile of FMD $(\leq 4.3)$.

In addition to effects on endothelial markers, changes in other factors of cardiovascular risk have been associated with the menopausal transition, such as the lipid profile, ${ }^{88}$ weight, and body fat distribution. ${ }^{89,90}$ The association between prevalence of cardiovascular risk during perimenopause and postmenopause and tunica media thickness (TMT) of the carotid was monitored in 314 women by Matthews et al.$^{88}$ In premenopausal patients, arterial and pulse pressure, LDL, HDL, triglycerides, and BMI values were predictors of TMT and the presence of atherosclerotic plaque after 5 years of menses cessation. In postmenopausal patients, only the increase in pulse pressure was a predictor of carotid intimal-medial thickness. ${ }^{91}$ These findings support the notion that women at higher risk of cardiovascular disease can be identified during premenopause, and it is in this period that strategies must be implemented to prevent the development of atherosclerosis in the postmenopausal years. 
Endothelial dysfunction can be curtailed by nonpharmacological measures, such as physical activity ${ }^{92}$ and weight loss, ${ }^{93}$ or pharmacological ones, such as statins and angiotensin converting enzyme (ACE) inhibitor. ${ }^{94.95}$ The indication for HT use must be individualized, taking into account the presence of climacteric symptoms and their impact on inflammatory and coagulation markers, since long-term benefits regarding atherosclerotic vascular disease have not yet been determined.

\section{RESUMO}

Maturana MA, Irigoyen MC, Sprtizer PM. Menopausa, estrogênios e disfunção endotelial: aspectos atuais. Clinics. 2007;62(1):77-86.

A menopausa é definida como a cessação permanente das menstruações. A doença cardiovascular é a principal causa de mortalidade em mulheres na pós- menopausa, em países desenvolvidos. A disparidade entre a incidência de doença cardiovascular entre mulheres na pré e pós menopausa tem sido atribuída a ações do estrogênio endógeno sobre o sistema cardiovascular e, em especial, sobre a função do endotélio vascular. $\mathrm{O}$ endotélio tem importante papel na homestase cardiovascular, seja no controle do tônus e permeabilidade vascular, ou da coagulação e resposta inflamatória. A disfunção endotelial está implicada na gênese da aterosclerose e de outras doenças crônicas, como diabete melito e hipertensão arterial. O uso farmacológico de estrogênio exerce influência sobre concentrações circulantes de marcadores do tônus vascular, inflamatórios, pró-trombóticos e fibrinolíticos, porém o impacto destas alterações sobre a doença aterosclerótica ainda não está determinado.

UNITERMOS: Menopausa. Função endotelial. Doença cardiovascular. Estrogênio. Terapia hormonal.

\section{REFERENCES}

1. WHO Scientific Group on Research on the Menopause in the 1990s Geneva, WHO technical report series; 866,1-107, 1996.

2. Pedro A O, Neto AMP, Paiva LH, Osis JM, Hardy E. Idade de ocorrência da menopausa natural em mulheres brasileiras:resultados de um inquérito populacional domiciliar. Cad. Saúde Pública. 2003;19:7-25.

3. Hunter MS. Emotional well-being, sexual behaviour and hormone replacement therapy. Maturitas. 1990;12:299-314.

4. Murray CJL, Lopez AD. The global burden of disease. World Health Organization. 1996

5. AHA Scientific Statement 2004. Evidence-Based Guidelines for Cardiovascular Disease Prevention in Women. Arterioscler Thromb Vasc Biol. 2004;24:29-50.

6. Assmann G, Carmena R, Cullen P, Fruchart JC, Jossa F, Lewis B, et al For The International Task Force for the Prevention of Coronary Heart Disease. Coronary Heart Disease: reducing the risk. A worldwide view. Circulation. 1999;100:1930-8.

7. Bush TL; Barret-Connor E, Cowan LD, Criqui MH, Wallace RB Suchindran CM. Cardiovascular mortality and noncontraceptive use of estrogen in women: results from the Lipid Research Clinics Program Follow-Up Study. Circulation. 1987;75:1102-9.

8. The writing group for the PEPI TRIAL. Effects of estrogen or estrogen/ progestin regimens on heart disease risk factors in postmenopausal women. The postmenopausal estrogen/progestin interventions (PEPI) trial. JAMA. 1995;273:199-208.
9. Grodstein F, Stampfer MJ, Colditz GA, Willet WC, Manson JE, Joffe M et al. Postmenopausal hormone therapy and mortality. N Engl J Med. 1997;336:1769-75.

10. Hulley S, Grady D, Bush T, Fulberg C, Herrington D, Riggs B, et al. For the heart and estrogen/ progestin replacement study (HERS) research group. Randomized trial of estrogen plus progestin for secondary prevention of coronary heart disease in postmenopausal women. JAMA. 1998;280:605-13

11. Writing Group for the Women's Health Initiative Investigators. Risks and benefits of estrogen plus progestin in healthy postmenopausal women. JAMA. 2002;288:321-33.

12. The women's health initiative steering committee. Effects of conjugated equine estrogen in postmenopausal women with hysterectomy. JAMA. 2004;291:1701-12;

13. Mombouli JV, Vanhoutte PM. Endothelial dysfunction: from physiology to therapy. J Mol Cell Cardiol. 1999;31:61-74.

14. Simionescu M, Simionescu N, Palade GE. Segmental differentiations of cell junctions in the vascular endothelium. The microvasculature. J Cell Biol. 1975;67:863-85.

15. Moncada S, Higgs EA, Vane JR. Human arterial and venous tissues generate prostacyclin (prostaglandin $\mathrm{x}$ ), a potent inhibitor of platelet aggregation. Lancet. 1977;1:18-20. 
16. Anderson R, Dart AM, Star J, Shaw J, Chin-Dusting JP. Plasma Creactive protein, but not protein S, VICAM-1, von Willebrand factor or E-selectin, is associated with endothelium dysfunction in coronary artery disease. Atherosclerosis. 2004;172:345-51.

17. Caramori PA, Zago AJ. Endothelial dysfunction and coronary artery disease. Arq Bras Cardiol. 2000;75:173-81.

18. Andrews NP, Hussain M, Dakak N, Ouyyumi AA. Platelet Inhibitory effect of nitric oxide in the human coronary circulation:impact of endothelial dysfunction. JACC. 2001;37: 510-6.

19. Furchgott RF, Zawadzki JV. The obligatory role of endothelial cells in the relaxation of arterial smooth muscle by acetylcholine. Nature. 1980;288:373-6.

20. Yang Y, Loscalzo J. Regulation of tissue factor expression in human microvascular endothelial cells by nitric oxide. Circulation 2000;101:2144-8.

21. Luz PL, Laurindo FRM, Chagas ACP. Endotélio \& doenças cardiovasculares. São Paulo: Atheneu. 2003;2:17-32.

22. Anderson T. Assessment and treatment of endothelial dysfunction in humans. J Am Coll Cardiol. 1999;34:631-8.

23. Ching HL, Watts GF, Dhaliwal SS, Barrett PH, Stuckey BG. Vascular function of forearm microcirculation in postmenopausal women with type 2 diabetes: potential benefit of hormone replacement therapy? Climateric. 2003;6:31-7.

24. Abdu TAM, Elhadd T, Pfeifer M, Clayton RN. Endothelial dysfunction in endocrine disease. TRENDS Endocrin Met. 2001;12:257-65.

25. Suwaidi JA, Hamasaki S, Higano S, Nishimura RA, Holmes DR Jr, Lerman A. Long-term follow-up of patients with mild coronary artery disease and endothelial dysfunction. Circulation 2000;101:948-54.

26. Ross R. Atherosclerosis-an inflammatory disease. N Engl J Med. 1999;340:115-25

27. Mercuro G, Longu G, Zoncu S, Cherchi A. Impaired forearm blood flow and vasodilator reserve in healthy postmenopausal women. Am Heart J. 1999;137:692-7.

28. Celermajer DS, Sorensen KE, Bull C, Robinson J, Deanfield JE. Endothelium-dependent dilation in the systemic arteries of asymptomatic subjects relates to coronary risk factors and their interaction. J Am Coll Cardiol. 1994;24:1468-74.

29. Pellegrino T, Storto G, Filardi PP, Sorrentino AR, Silvestro A, Petretta $\mathrm{M}$, et al. Relationship between brachial artery flow-mediated dilation and coronary flow reserve in patients with peripheral artery disease. $\mathrm{J}$ Nucl Med. 2005;46:1997-2002.

30. Neuteufl T, Kazenschlager R, Hassan A. Systemic endothelial dysfunction is related to the extent and severity of coronary artery disease. Atherosclerosis. 1997;129:111-8

31. Fathi R \& Marwick TH. Noninvasive tests of vascular function and structure: why and how to perform them. Am Heart J. 2001;141:694703.

32. Rossi R, Cioni E, Nuzzo A. Endothelial-dependent vasodilation and incidence of type 2 diabetes in a population of healthy postmenopausal women. Diabetes Care. 2005;28:702-7.
33. Ryliskyte L, Ghiadoni L, Plantiga Y. High-frequency ultrasonographic imaging of the endothelium-dependent flow-mediated dilatation (FMD) in a brachial artery: normative ranges in a group of low $\mathrm{CV}$ risk subjects of different ages. Proc West Pharmacol Soc. 2004;47:67-8.

34. Ghiadoni L, Taddei S, Virdis A, Sudano J, Di Legge V, Meola M, et al Endothelial function and common carotid artery wall thickening in patients with essential hypertension. Hypertension. 1998;32:25-32.

35. Tentolouris C, Tousolis D, Antoniades C, Bosinakou E, Kotsopoulos M, Trikas A, et al. Endothelial function and proinflammatory cytokines in patients with ischemic heart disease and dilated cardiomyopathy. Int J Cardiol. 2004;94:301-5.

36. Sousa MG, Yugar-Toledo JC, Rubira MC, Ferreira-Melo SE, Souza W, Consolin-Colombo F, et al. Ascorbic acid improves venous and arterial endothelium-dependent dilation in smokers. Acta Pharmacologica Sinica. 2005; 26:447-52

37. Playford DA \& Watts GF. Special article: noninvasive measurement of endothelial function. Clin Exp Pharmacol Physiol. 1998;25:640-3.

38. Sanada M, Higashi Y, Nakagawa K, Kodama J, Tsuda I, Nagai N, et al Comparison of forearm endothelial function between premenopausal and postmenopausal women with or without hypercholesterolemia. Maturitas. 2003;44:307-15.

39. Schindler G, Grossmann M, Dobrev D, Francke K, Pittrow D, Kirch W Reproducibility of dorsal hand vein responses to phenylephrine and prostaglandin $\mathrm{F}_{2 \mathrm{u}}$ using the dorsal hand vein compliance method. J Clin Pharmacol 2003;43:228-36.

40. Kalantaridou SN, Naka KK, Papanikolaou E, Kazakos N, Kravariti M, Calis KA, et al. Impaired endothelial function in young women with premature ovarian failure: normalization with hormone therapy. J Clin Endocrinol Metab. 2004;89:3907-13

41. Sanada M, Higashi Y, Nakawaga K, Tsuda M, Kodama I, Kimura M, et al. A comparison of low-dose and standard-dose oral estrogen on forearm endothelial function in early postmenopausal women. J Clin Endocrinol Metab. 2003; 88:1303-09.

42. Taddei S, Virdis A, Ghiadoni L, Mattei P, Sudano I, Bernini G, et al. Menopause is associated with endothelial dysfunction in women. Hypertension. 1996;28:575-82

43. Subbiah MR. Estrogen replacement therapy and cardioprotection mechanisms and controversies. Braz J Med Biol Res. 2002;35:271-76.

44. Mendelsohn ME, Karas RH. Mechanisms of disease: the potential effects of estrogen on the cardiovascular system. N England J Med. 1999;340:1801-11.

45. Khalil RA. Sex hormones as potential modulators of vascular function in hypertension. Hypertension. 2005;46:249-54.

46. Hermenegildo C, Oviedo PJ, Cano A. Cyclooxygenases regulation by estradiol on endothelium. Curr Pharm Des. 2006;12:205-15.

47. Nilsson S, Gustafsson JA. Estrogen receptor transcription and transactivation. Basic aspects of estrogen action. Breast Cancer Res. 2000;2:360-6.

48. Barchiese F, Jackson EK, Gillespie DJ, Zacharia LC, Fingerle J, Dubbey RK. Methoxyestradiols mediate estradiol-induced antimitogenesis in human aortic SMCs. Hypertension. 2002;39:874-9. 
49. Pare Gary, Krust A, Karas R, Dupont S, Aronovitz M, Chambom P, et al. Estrogen receptor-a mediates the protective effects of estrogen against vascular injury. Circ Res. 2002;90:1087-92.

50. Scheuer J, Malhotra A, Schaible TF, Capasso J. Effects of gonadectomy and hormonal replacement on the rat hearts. Circ Res. 1987; 61:12-9.

51. Mosca L, Collins P, Herrington DM, Mendelson ME, Pastermak RC, Robertson RM, et al. Hormone replacement therapy and cardiovascular disease. A statement for healthcare professionals from the AHA. Circulation. 2001;104:499-503.

52. Spritzer PM, Maturana MA, Farias A, Bittencourt PH Jr. Nitric oxide levels and hyperinsulinemia in postmenopausal women: relationship with hormonal, metabolic and anthropometric measurements. In: Genazzani Arm Artini PG, Petraglia F, editors. Recent research in gynecological endocrinology. New York: Parthenon; 2001. p.185-8.

53. Sutton-Tyrrell K, Wildman RP, Matthews KA, Chae C, Lasley BL,Brockwell S, Pasternak RC, et al. Sex hormone-binding globulin and the free androgen index are related to cardiovascular risk factors in multiethnic premenopausal and perimenopausal women enrolled in the Study of Women Across the Nation (SWAN). Circulation. 2005;111:1242-9.

54. Phillips GB, Pinkernell BH, Jing TY. Relationship between serum sex hormones and coronary artery disease in postmenopausal women. Arterioscler Thromb Vasc. 1997;17:695-701.

55. Lee CC, Kasa-Yubo JZ, Supiano MA. Androgenicity and obesity are independently associated with insulin sensitivity in postmenopausal women. Metabolism. 2004;53:507-12.

56. Haffner SM, Valdez RA, Morales PA, Hazuda HP, Stern MP. Decreased sex hormone-binding globulin predicts noninsulin-dependent diabetes mellitus in women but not in men. J Clin Endocrinol Metab. 1993;77:56-60.

57. Ding EL, Song Y, Maliki VS, Liu S. Sex differences of endogenous sex hormones and risk of type 2 diabetes: a systematic review and metaanalysis. JAMA. 2006;295:1288-99.

58. Maturana MA and Spritzer PM. Association between hyperinsulinemia and endogenous androgen levels in peri- and postmenopausal women. Metabolism. 2002;51:238-43.

59. Higashi Y, Sanada M, Sasaki S, Nakagawa K, Goto C, Matsuura H, et al Effect of estrogen replacement therapy on endothelial function in peripheral resistance arteries in normotensive and hypertensive postmenopausal women. Hypertension. 2001;37:651-7.

60. Duschek Ejj, Stehouwer CDA, Valk-DE Roo, GW. Raloxifene, conjugated oestrogen and endothelial function in postmenopausal women. J Intern Med. 2003;254:85-94

61. Lima SMR, Aldrighi JM, Consolin-Colombo FM, Mansur A, Rubira MC, Krieger EM, et al. Acute administration of 17b-estradiol improves endothelium-dependent vasodilation in postmenopausal women. Maturitas. 2005;50:266-74

62. Grady D, Herrington D, Brittner V, Blumenthal R, Davidson M, Hlatky $\mathrm{M}$, et al. For the HERS Research Group. Cardiovascular disease outcomes during 6.8 years of hormone theraphy: Heart and Estrogen/ progestin Replacement Study follow-up (HERS II). JAMA. 2002;288:49-57.

63. Teede HJ, McGrath B P, Smolich JJ, Malan E, Kotsopoulou M, Liang YL, et al. Postmenopausal hormone replacement therapy increases coagulation activity and fibrinolysis. Arterioscler Thromb Vasc Biol. 2000;20:1404-16
64. Brown NJ, Abbas A, Byrne D, Brown NJ, Abbas A, Byrne D, et al. Comparative effects of estrogen and angiotensin-converting enzyme inhibition on plasminogen activator inhibitor-1 in healthy postmenopausal women. Circulation. 2002;105:304.

65. Gottsater A, Rendell M, Hulthen UL. Hormone replacement therapy in healthy postmenopausal women: a randomized, placebo-controlled study of effects on coagulation and fibrinolytic factors. J Intern Med. 2001;249:237-46

66. Perera M, Sattar N, Petrie JR, Hillier C, Small M, Connell JM, et al. The effects of transdermal estradiol in combination with oral norethisterone on lipoproteins, coagulation, and endothelial markers in postmenopausal women with type 2 diabetes: a randomized, placebo-controlled study. J Clin Endocrinol Metab. 2001;86:1140-3.

67. Rabbani LE, Seminário NA, Sciacca RR. Oral conjugated equine estrogen increases plasma von Willebrand factor in postmenopausal women. JACC. 2002;40:1991-11.

68. Scarabin PY, Oger E, Plu-Bureau G. Differential association of oral and transdermal oestrogen replacement therapy with venous thromboembolism risk. Lancet 2003;362:428-32.

69. Wender MCO, Vitola D, Spritzer PM. Percutaneous 17 beta-estradiol replacement therapy in hypertensive postmenopausal women. Braz J Med Biol Res. 1997;30:1047-53.

70. Vilodre LC, Wender MC, Castro JÁ, Reis FM, Ruschel S, Magalhães JÁ, et al. Endometrial response to cyclic regimen of percutaneous 17 beta-estradiol and low-dose vaginal micronized progesterone in women with mild to moderate hypertension. Gynecol Endocrinol. 2003; $17: 323-8$.

71. Spritzer PM, Vitola D, Vilodre LC, Wender MC, Reis FM, Ruschel S, et al. One year follow-up of hormone replacement therapy with percutaneous estradiol and low-dose vaginal natural progesterone in women with mild to moderate hypertension. Exp Clin Endocrin Diabetes. 2003;111:267-73.

72. Hu P, Greendale GA, Palla SC, Reboussin BA, Henrrington DM, BarretConnor E, et al. The effects of hormone therapy on the markers of inflammation and endothelial function and plasma matrix metalloproteinase-9 level in postmenopausal women: the postmenopausal estrogen progestin intervention (PEPI) trial. Atherosclerosis. 2006;185:347-52.

73. Sumino H, Ichikava S, Kasama S, Takahashi T, Kumakura H, Takayama Y, et al. Different effects of oral conjugated estrogen and transdermal estradiol on arterial stiffness and vascular inflammatory markers in postmenopausal women. Atherosclerosis. 2006; In Press.

74. Wakatsuki A, Ikenoue N, Shinohara K. Effect of lower dosage of oral conjugated equine estrogen on inflammatory markers and endothelial function in healthy postmenopausal women. Arterioscler Thromb Vasc Biol. 2004;24:571-6.

75. Wakatsuki A, Okatani Y, Ikenove N, Fukaya T. Effect of medroxyprogesterone acetate on vascular inflammatory markers in postmenopausal women receiving estrogen. Circulation. 2002;105:1436.

76. Lakoski SG, Herrington DM. Effects of hormone therapy on C-reactive protein and IL-6 in postmenopausal women: a review article. Climacteric. 2005;8:317-26.

77. Mather KJ, Norman EG, Jerilynn J, Prior JC, Elliott TG. Preserved forearm endothelial responses with acute exposure to progesterone: a randomized cross-over trial of $17-\beta$ estradiol, progesterone, and $17-\beta$ estradiol with progesterone in healthy menopausal women. JCEM. 2000;85:4644-9. 
78. Maturana MA, Rubira MC, Breda V, Irigoyen MC, Spritzer PM. Endothelial-dependent vasodilation in postmenopausal women: rapid effects of non-oral 17 beta-estradiol. In: $11^{\text {th }}$ World Congress on the Menopause 2005. Buenos Aires, Argentina.

79. Saitta A, Altavilla D, Cucinotta D, Morabito N, Frisina N, Corrado F, et al. Randomized, double-blind, placebo-controlled study on effects of raloxifene and hormone replacement therapy on plasma no concentrations, endothelin-1 levels, and endothelium-dependent vasodilation in postmenopausal women. Arterioscler Thromb Vasc Biol. 2001;21:1512-9.

80. Balci H, Altunyurt S, Acor B. Effects of transdermal estrogen replacement therapy on plasma levels of nitric oxide and plasma lipids in postmenopausal women. Maturitas. 2005;50:289-93.

81. Ceballos C, Ribes C, Amado JA. Venous endothelial function in postmenopausal women who are receiving long-term estrogen and progestagen therapy. Fertility and Sterility. 2000;74:268-73.

82. Orshal JM \& Khalil RA. Gender, sex hormones and vascular tone. Am J Physiol Regul Integr Comp. 2004;286:233-49.

83. Rosano GM, Vitale C, Silvestri A, Fini M. Metabolic and vascular effect of progestins in post-menopausal women. Implications for cardioprotection. Maturitas. 2003;46:S17-29

84. White WB, Hanes V, Chauhan V, Pitt B. Effects of a new hormone therapy, drospirenone and 17-beta-estradiol, in postmenopausal women with hypertension. Hypertension. 2006;48:246-53.

85. Sanada M, Higashi Y, Nakagawa K, Tsuda M, Kodama I, Nagai N, et al. Combination therapy of low-dose medroxyprogesterone acetate and oral estrogen does not affect endothelial function in the forearms of postmenopausal women. Menopause. 2002;9:360-6.

86. Wakatsuki A, Okatani Y, Ikenoue N, Fukaya T. Effect of medroxyprogesterone acetate on endothelium-dependent vasodilation in postmenopausal women receiving estrogen. Circulation. 2001;104:1773-8.
87. Thorand B, Baumert J, Chambless L, Meisinger C, Kobb H, Doring A et al. For the MONICA/KORA study group. Elevated markers of endothelial dysfunction predict type 2 diabetes mellitus in middle-aged men and women from the general population. Arterioscler Thromb Vasc Biol. 2006;26:398-405

88. Matthews KA, Meilahn E, Kuller L, Kelsey SF, Caggiula AW, Wing RR. Menopause and risk factors for coronary heart disease. N Engl J Med. 1989;321:641-6.

89 Poehlman ET, Toth MJ, Gardner AW. Changes in energy balance and body composition at menopause: a controlled longitudinal study. Ann Intern Med. 1995;123:673-5.

90. Donato GB, Fuchs SC, Oppermann K, Bastos C, Spritzer PM. Association between menopause status and central adiposity measured at different cutoffs of waist circumference and waist-to-hip ratio. Menopause. 2006;13:280-5.

91. Matthews KA, Kuller LH, Sutton-Tyrrel K, Chang YF. Changes in cardiovascular risk factors during the perimenopause and postmenopause and carotid artery atherosclerosis in healthy women. Stroke. 2001;32:1104-11

92. Harvey PJ, Picton PE, Su WS, Morris BL, Notarius CF, Floras JS Exercise as an alternative to oral estrogen for amelioration of endothelial dysfunction in postmenopausal women. Am Heart J. 2005;149:291-7.

93. Vázquez LA, Pazoz F, Berrazueta JR. Effects of changes in body weight and insulin resistance on inflammation and endothelial function in morbid obesity after bariatric surgery. J Clin Endocrinol Metab. 2005;90:316-22.

94. Dupuis J, Tardif JC, Rouleau JC.Intensity of lipid lowering with statins and brachial artery vascular endothelium reactivity after acute coronary syndromes (from the BRAVER trial). Am J Cardiol. 2005;96:1207-13.

95. Deja MA, Golba KS, Widenka K, Mrozek R, Biernat J, Kolowca M, et al. Angiotensin-converting enzyme inhibitors reveal non-NO-, nonprostacycline-mediated endothelium-dependent relaxation in internal thoracic artery of hypertensive patients. Int J Cardiol. 2005;102:45560. 